\title{
Anion influence in lead removal from aqueous solution by deposition onto a vitreous carbon electrode
}

\author{
G. Carreño, E. Sosa, I. González, C. Ponce-de-León, N. Batina, \\ M.T. Oropeza * \\ Universidad Autónoma Metropolitana-Iztapalapa. Departamento de Química. Apdo Postal 55-534, 09340. México D.F. México
}

Received 13 August 1998; received in revised form 27 September 1998

\begin{abstract}
We investigated the electrolytic removal of $\mathrm{Pb}(\mathrm{II})$ from aqueous solutions containing different electrolytes (nitrate, chloride or sulfate), by electrolysis onto reticulated vitreous carbon electrode (RVC). The efficiency of the electrolytic process of lead removal was found to be a function of electrolyte composition. The chloride containing electrolyte, provided the highest efficiency of lead removal, while removing $\mathrm{Pb}$ (II) from the sulfate electrolytes turned out to be a very difficult and high energy consuming process. Cyclic voltammetry and the atomic force microscopy (AFM) were used to characterize lead deposits on RVC and fractured vitreous carbon (FVC) electrodes surface. Our study showed that in the chloride solution, a significantly larger amount of lead deposit was formed than in the sulfate electrolyte. Since the same phenomenon was observed with both electrode types, the FVC electrode is established as an appropriate laboratory model for studying the RVC, which is often used in industrial applications. AFM analysis revealed that lead deposits formed from different electrolyte solutions possess different surface morphologies, indicating different mechanism of formation or different kinds of interactions between the metal adlayer and the adsorbed anions. A highly dense lead deposit, spread all over the electrode surface, in the form of a 2-D film, was found when using the chloride-containing electrolyte. This was attributed to the surface annealing effect and the increased number of nucleation sites due to chloride coadsorption at the electrode surface. Deposits formed from the sulfate electrolyte consisted of numerous, isolated and rather small lead clusters, indicating that deposition from sulfate solutions was inhibited by the formation of the passivated salt adlayer over the lead clusters. 1999 Elsevier Science Ltd. All rights reserved.
\end{abstract}

\section{Introduction}

Among the many technologies developed and currently used for removal of transition and heavy metals from efflucnts and environmental waters, clectrolytic methods possess many advantages. They are relatively simple, rapid and efficient to perform and they do not produce environmentally hazardous byproducts. It is not surprising, therefore, that many commercial systems based on such electrochemical techniques have been developed for removal of different metals, includ-

\footnotetext{
* Tel.: $\quad+52-5-724-4670 ;$ fax: $\quad+52-5-724-4666 ;$ e-mail: mtog $(a)$ xanum.uam.mx
}

ing: $\mathrm{Ag}(\mathrm{I}), \mathrm{Cu}(\mathrm{II}), \mathrm{Pb}(\mathrm{II}), \mathrm{Hg}(\mathrm{II}), \mathrm{Zn}(\mathrm{I})$ and $\mathrm{Cd}(\mathrm{II})$ from industrial effluents [1-5].

Achieving optimum efficiency in the electrochemical recovery of metal ions from real waste solutions, however, is a complex problem [2] involving some interesting technological and fundamental challenges. Wastewater is a very complex mixture of different species with a variety of different physico-chemical properties. The metal-ion removal process, which is often carried out by metal deposition from solution to the electrode substrate, is inherently ill-defined in terms of deposition mechanisms, kinetics and other important reaction parameters $[1,5]$. In order to improve the characteristics of the metal deposit as a final product, various components, usually molecular additives, are 
often added in many commercial electrolytic baths [1] These systems thus become even more complex and less definable.

The mechanisms and kinetics of metal deposition processes on different substrates and from different electrolyte solutions have been favorite subjects of many fundamental electrochemical studies over the last few decades [6-10]. Simple, well-defined model systems, far different from the complex reality, are generally investigated. The results of such studies have contributed to the understanding of electrode processes, thus aiding in the design of various types of electrochemical reactors for more efficient metal removal processes.

Despite obvious progress, the complete understanding of the metal removal process and those factors important for optimizing the corresponding reactions has yet to be achieved. The metal removal is based on and closely related to the understanding of metal deposition process and in many aspects depends on physico-chemical properties of the electrode surface, metal-substrate, anion-metal and anion-substrate interactions. The influences of the electrolyte composition, electrode substrate characteristics and different factors affecting the metal deposition process are already known through studies considering single-crystal metal electrodes [11-15]. However, since these electrodes are not suitable for technological applications, the findings are not directly applicable to electrode systems of different materials and characteristics (i.e. vitreous carbon electrode) which are often used in industry.

The mercury electrode surface, frequently used in past fundamental studies for defining the role of specific adsorbed anions and their contribution to reduction of metal ions, provided data which are also difficult to apply to practical applications. Using this system, metal ions were showed to coadsorb in presence of adsorbable anions [16,17]. Mercury, however, is no longer used as an electrode in industrial processes. In order to define correctly the processes on technologically important electrode surfaces, the same or at least similar electrode material should be used in academic studies.

We report on our study of $\mathrm{Pb}$ (II) removal from aqueous electrolytes containing chloride, sulfate and nitrate ions based on $\mathrm{Pb}$ (II) deposition on reticulated vitreous carbon (RVC) and fractured vitreous carbon (FVC) electrodes. The RVC electrode is more appropriate for industrial use since it possesses a higher specific area per unit volume: $66 \mathrm{~cm}^{2} \mathrm{~cm}^{-3}$ vs. the geometric area of the FVC in two dimensions. This fact accounts for the increases in the current and thus the rate of product formation. The RVC electrode was purchased from Electrosynthesis Co. USA and the FVC electrode was prepared from a vitreous carbon rod of $0.5 \mathrm{~cm}$ diameter, (Alfa, AESAR USA) by man- ual fracture. In our preliminary surface characterization study [18], we found that these two electrode surfaces possess rather similar characteristics. Therefore we expected FVC to serve as a very good model electrode surface for examining processes of the RVC electrode, which is more appropriate of the two for industrial use.

We also considered the influence of anions on the $\mathrm{Pb}$ (II) deposition reaction, and consequently, on the efficiency of the $\mathrm{Pb}(\mathrm{II})$ removal process. Ponce de Leon and Pletcher [2], studied removal of $\mathrm{Pb}(\mathrm{II})$ from aqueous solutions of perchlorate, nitrate, tetrafluoroborate, chloride and sulfate $(\mathrm{pH} 2)$, by electrodeposition process, at RVC electrode. Using electrochemical techniques, they found that the potential of deposit formation and the extent of $\mathrm{Pb}(\mathrm{II})$ removal during electrolysis depended on the type of anion present in solution. A simple, mass transport controlled process was found only when the solution anion was chloride. In nitrate, perchlorate and tetrafluoroborate, $\mathrm{Pb}(\mathrm{II})$ removal proceeded more slowly than the rate predicted by the model, which assumed mass transport controlled process. This suggested that these anions are noncomplexing agents, without ability to adsorb on the electrode surface. The chloride ion, on the other hand, seems to adsorb on the RVC electrode surface, possibly catalyzing the $\mathrm{Pb}(\mathrm{II})$ deposition by an early growth of lead on the carbon surface. Removal of lead from sulphate solutions was only possible at very negative potentials, beyond the plateau of the reduction wave in the $I-E$ curves.

Our results support these previous findings, also showing that removal of $\mathrm{Pb}$ (II) from chloride-containing electrolyte is the most efficient process. In order to relate removal and deposit formation, we also focussed on $\mathrm{Pb}$ deposit characterization on both RVC and FVC. Besides the electrochemical techniques (potentiostatic electrolysis, voltammetry), for the surface characterization atomic force microscopy (AFM), was used. AFM has proven to be a reliable tool for evaluation of surface morphology characteristics providing valuable qualitative information regarding the mechanism and quality of deposit adlayers, at the electrode surface [19-27].

\section{Experimental}

Electrochemical experiments involving the electrolysis of lead from aqueous solution and cyclic voltammetry were performed using a potentiostat-galvanostat Voltamaster 2, from Radiometer, France. The electrolysis experiments were performed using the cell and flow circuit described in a previous work $[2,28]$. On the other hand a classical three-electrode cell, with a reference, counter and working electrode was used for 
the voltametric studies. Oxygen was removed by purged nitrogen stream. A saturated calomel electrode (SCE) served as the reference electrode and a graphite rod as a counter or auxiliary electrode. Two kinds of vitreous carbon electrodes were used for working electrodes: reticulated vitreous carbon (RVC) and fractured vitreous carbon. (FVC) Reticulated vitreous carbon was provided from Electrosynthesis Co. Inc. USA. The RVC electrode was a $1.0 \times 0.5 \mathrm{~cm}$, rectangular piece, rinsed before use with ultrapure water. The FVC electrode was prepared from a vitreous carbon rod $(0.5 \mathrm{~cm}$, diameter $)$ purchased from Alfa, AESAR, USA. After manual fracture, each time the electrode surface was evaluated visually and only electrodes with very similar surface areas were selected for further use. The surface area, for all electrodes was approximately $0.2 \mathrm{~cm}^{2}$. In order to make the electrical contact for both electrodes, a Leit-C carbon glue, Neubauer Chemikalien, Germany, was used. As in the case of RVC, utilization of FVC required no special preparation besides other than rinsing with water.

Electrochemical experiments were carried out with the following different electrolytic solutions at $\mathrm{pH} 2$, in $0.5 \mathrm{M} \mathrm{NaCl}, 0.5 \mathrm{M} \mathrm{NaNO}$ and $0.5 \mathrm{M} \mathrm{Na}_{2} \mathrm{SO}_{4}$. Lead concentration in electrolysis experiments varied between 0.024 and $0.4 \mathrm{mM}$. In the cyclic voltammetry measurements, the concentration of the electroactive species $\mathrm{Pb}(\mathrm{II})$ was kept constant at $0.024 \mathrm{mM}$. In different electrolytes, the corresponding lead salt was used, for example in the nitrate electrolyte solution $\mathrm{Pb}\left(\mathrm{NO}_{3}\right)_{2}$, was used.

For electrolyte solution preparation, the following chemicals, all analytical grade, were used: $\mathrm{HCl}, \mathrm{HNO}_{3}$, $\mathrm{H}_{2} \mathrm{SO}_{4}, \mathrm{NaCl}, \mathrm{PbCl}_{2}, \mathrm{~Pb}\left(\mathrm{NO}_{3}\right)_{2}, \mathrm{NaNO}_{3}, \mathrm{PbSO}_{4}$, $\mathrm{Na}_{2} \mathrm{SO}_{4}$. All solutions were prepared using ultrapure Milli-Q(iii) water.

The progress of the $\mathrm{Pb}(\mathrm{II})$ electrolysis (remediation) was monitored by checking the lead concentration in the electrolyte solution. $\mathrm{Pb}(\mathrm{II})$ concentrations were determined by atomic absorption spectroscopy (AAS) using a Perkin Elmer 2380PE model 157 spectrometer with an oxygen/acetylene flame. Samples for analysis were taken every $5 \mathrm{~min}$.

Alomic force microscopy (AFM). Nanoscope III, (Digital Instruments, USA) was used for visualization of the bare and lead covered FVC electrode surface. The samples for AFM visualization were prepared in three different electrolytes: nitrate, sulfate and chloride. AFM analysis was performed ex situ, under laboratory atmosphere. AFM was operated in contact mode, with standard geometry silicon nitride probes. Images were collected in slow scan rate of $1 \mathrm{~Hz}$. In order to evaluate the progress of $\mathrm{Pb}$ deposition process, the electrode surface was regularly visualize before and after the deposition process at different deposition overpotentials. Morphological characteristics of a lead free and lead covered FVC electrode surface were quantitatively evaluated using the AFM, Nanoscope III software package. For each sample several images were recorded at different places. No destruction of sample was notice during imaging. All images in this paper are presented in the 'height mode', so that higher parts of the surface appear brighter in the image. Images are plotted in a 3-D presentation mode, with approximately the same $x-y$ and $z$ scale.

\section{Results}

\subsection{Constant potential electrolysis of lead onto RVC electrode}

In order to understand the influence of different electrolytes on the electrochemical remittance of $\mathrm{Pb}(\mathrm{II})$ from the aqueous solutions, we performed a constant potential electrolysis study. Electrolysis was carricd out from $7 \mathrm{ppm} \mathrm{Pb}(\mathrm{Il})$ aqueous solution in $0.5 \mathrm{M}$ inert electrolyte solutions of the appropriate sodium salt, adjusted to $\mathrm{pH} 2$ with the corresponding acid, using the RVC electrode mounted in a flow-by cell. In each electrolyte, the process was carried out at different potentials based on the nature of $\mathrm{Pb}$ (II) deposition in different media. In order to perform electrolysis consistently as a mass transfer controlled process in different electrolyte solutions, different overpotentials should be applied as demonstrated previously [2]. In the chloride solution, electrolysis was carried out at $-0.80 \mathrm{~V}$ vs. SCE and in the nitrate and sulfate media, at even more cathodic potentials of -1.00 and $-1.20 \mathrm{~V}$, respectively. These potentials were selected after a detailed search in the long range of potentials [28].

Progress of $\mathrm{Pb}(\mathrm{II})$ electrolysis (depletion) was monitored by checking lead concentration in solution with atomic absorption spectroscopy (AAS). Fig. 1 shows the depletion of the normalized $\mathrm{Pb}(\mathrm{II})$ solution concentration (AAS data) as a function of the electrolysis time. For all electrolytes, the depletion curves follow the expected exponential decay, indicating a mass transport control [2]. Different depletion rates were observed for the different electrolytes. The fastest $\mathrm{Pb}$ (II) depletion rate (decrease of $\mathrm{Pb}(\mathrm{II})$ concentration in the solution) was observed for the chloride-containing electrolyte. The slowest depletion was recorded in the sulfate-containing electrolyte. Note that in the sulfate solution (curve c, Fig. 1). even after $45 \mathrm{~min}$, removal of $\mathrm{Pb}$ (II) was still approximately $10 \%$ less than for the chloride and nitrate electrolytes (curves a and b, respectively, Fig. 1). In order to compare the efficiency, we took into account the total charge necessary to remove $90 \%$ (an arbitrary point) of the initial lead concentration (7 ppm). Because the $\mathrm{Pb}$ (II) depletion rate differed for the different electrolytes, 


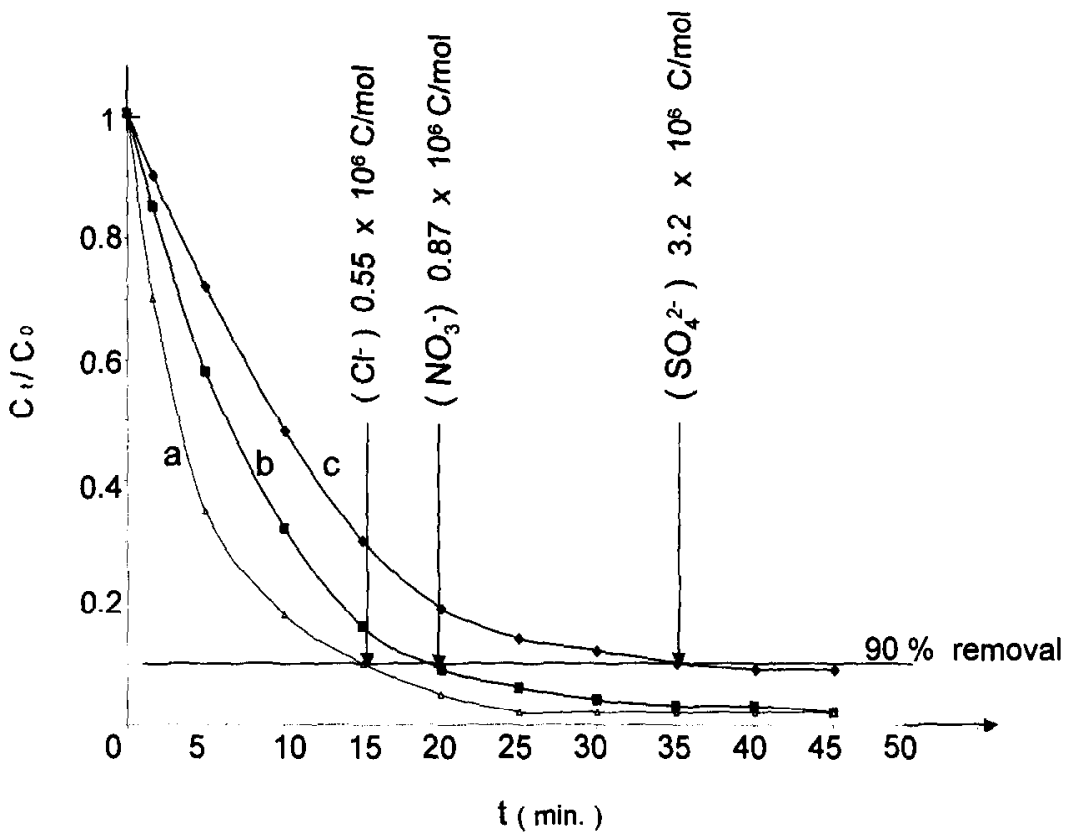

Fig. 1. Decay of the normalized $\mathrm{Pb}(\mathrm{II})$ concentration vs. time during constant potential electrolysis on $\mathrm{RVC}$. The electrolysis was performed at different applied potential $\left(E_{\text {app }}\right)$, in three different electrolytes: (a) chloride, $E_{\text {app }}=-0.80 \mathrm{~V},(\mathrm{~b})$ nitrate $E_{\text {app }}=-1.0$ $\mathrm{V}$ and (c) sulfate $E_{\mathrm{app}}=-1.2 \mathrm{~V}$ vs. SCE. The charge related to $\mathrm{Pb}(\mathrm{II})$ depletion of $90 \%$ is shown in the figure.

$90 \%$ of the total $\mathrm{Pb}$ (II) removal was achieved in different time frames: $15 \mathrm{~min}$ for $\mathrm{Cl}^{-}, 20 \mathrm{~min}$ for $\mathrm{NO}_{3}^{-}$and $35 \mathrm{~min}$ for $\mathrm{SO}_{4}^{2-}$ solution. Accordingly, the total charge consumption $\left(Q_{\text {TOT }}\right)$ during the electrolysis process (see Table 1) also increased in the same order from $\mathrm{Cl}^{-}$, to $\mathrm{NO}_{3}^{-}$and to $\mathrm{SO}_{4}^{2-}$. Based on these data and the AAS-analysis (monitoring $\mathrm{Pb}(\mathrm{II})$ concentration in solution), the efficiency of the removal process $(\varphi \mathbf{e})$ and total electrolytic energy consumption $\left(E_{\mathrm{s}}\right)$, were estimated (Table 1). Maximum efficiency for $\mathrm{Pb}$ (II) removal and the lowest energy consumption per mol of extracted material, were achieved in the case of the chloride-containing electrolyte. $\mathrm{Pb}$ (II) removal from the sulfate-containing electrolyte, on the other hand, was very difficult, requiring 30 times more energy $(\mathrm{kWh} / \mathrm{mol})$ than removal from the chloride-containing electrolyte. These results are in agreement with previous reports [2] which also found that recovery from the sulfate electrolyte required more energy than removal from chloride electrolyte. The reason for this difference in behavior has yet to be explained. It is important to note that the current efficiencies for lead electrolysis represented in Table 1 are lower than those reported in a previous work [2]. This is probably due to the small initial $\mathrm{Pb}$ (II) concentration, which produces a current of the same order of magnitude as the residual current (capacitance processes, plus solvent electrolysis).

\subsection{Cyclic voltammetry on the RVC electrode}

Cyclic voltammetry was employed to examine the basis for the differential electrolyte efficiencies in the lead recovery process. With these experiments, we shifted our attention towards the formation and characterization of the $\mathrm{Pb}$ deposit at the $\mathrm{VC}$ electrode

Table 1

Parameters related to the constant potential electrolysis using RVC electrode, for $\mathrm{Pb}(\mathrm{II})$ removal to $90 \%$. From three different electrolytes, corresponding to $\mathrm{Fig}$, 1. The initial $\mathrm{Pb}(\mathrm{II})$ concentration was $7 \mathrm{ppm}$

\begin{tabular}{llllll}
\hline System & $\begin{array}{l}\text { Electrolysis potential } \\
E_{\text {app }}(\mathrm{V} / \mathrm{SCE})\end{array}$ & $\begin{array}{l}\text { Removal } \\
\text { Time } t(\mathrm{~min})\end{array}$ & $\begin{array}{l}\text { Total electrical charge } \\
Q_{\text {TOT exp }} \times 10^{-6}(\mathrm{C} / \mathrm{mol})\end{array}$ & $\begin{array}{l}\text { Current } \\
\text { efficiency } \varphi \mathrm{e}(\%)\end{array}$ & $\begin{array}{l}\text { Electrolytic energy } \\
\text { consumption } E_{\mathrm{s}}(\mathrm{kWh} / \mathrm{mol})\end{array}$ \\
\hline $\mathrm{SO}_{4}^{2-}$ & -1.2 & 35 & 3.2 & 6 & 2.65 \\
$\mathrm{NO}_{3}^{-}$ & -1.0 & 20 & 0.87 & 22 & 0.21 \\
$\mathrm{Cl}^{-}$ & -0.8 & 15 & 0.55 & 35 & 0.08 \\
\hline
\end{tabular}




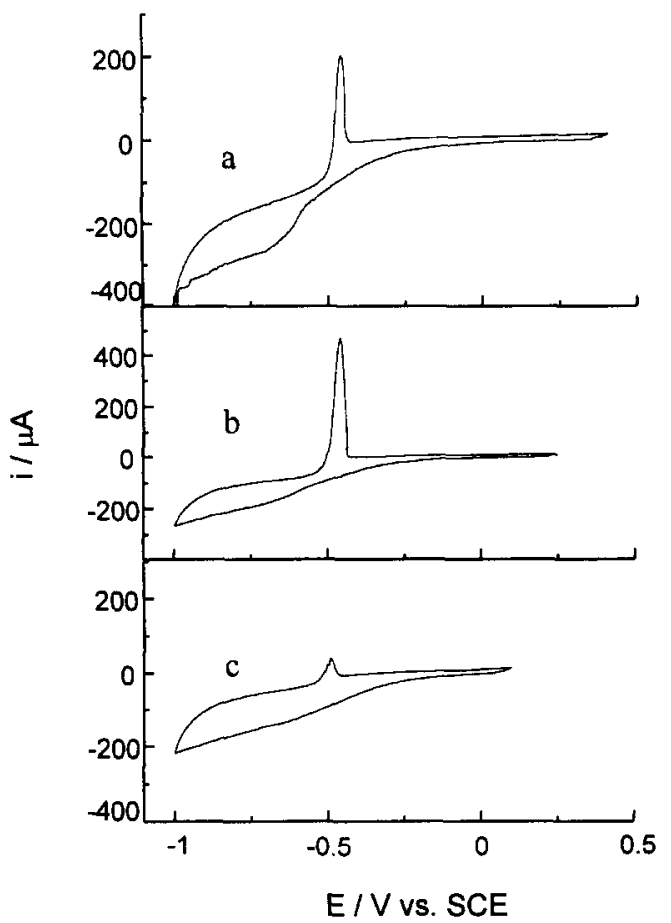

Fig. 2. Voltammograms for RVC electrode, obtained in 0.024 $\mathrm{mM} \mathrm{Pb}(\mathrm{II})$ solution in different electrolyte solution: (a) nitrate, (b) chloride and (c) sulfate. The scan rate is $5 \mathrm{mV} / \mathrm{s}$.

surface and evaluation of the role of anions during formation of the $\mathrm{Pb}$ deposit. First, the experiments were carried out with RVC electrodes. Fig. 2 shows the set of cyclic voltammograms obtained in different electrolytes containing $0.024 \mathrm{mM} \mathrm{Pb}$ (II) for the RVC electrodes. In all electrolytes, the $\mathrm{Pb}(\mathrm{II})$ deposition wave (at $-0.600 \mathrm{~V}$ vs. SCE) was poorly-defined, possibly due to the similar magnitude of both capacitive and faradaic currents. The small faradaic current is due to the low $\mathrm{Pb}$ (II) concentration and the large capacitive current is due to the large specific area, usually associated with RVC electrodes. Indeed, the $\mathrm{Pb}(\mathrm{II})$ deposition wave was hidden by a constant increase of the cathodic current. Interestingly, when comparing the behavior among the different electrolytes, we observed a difference in the size of the $\mathrm{Pb}$ dissolution peaks. Regardless

Table 2

Charge of the Pb-dissolution peak (anodic) estimated from voltammograms in Fig. 2 (RVC) and in Fig. 3 (FVC)

\begin{tabular}{lll}
\hline System & RVC- $Q_{\mathrm{A}}(\mathrm{mC})$ & FVC- $Q_{\mathrm{A}}(\mathrm{mC})$ \\
\hline $\mathrm{SO}_{4}^{2-}$ & 0.019 & 0.0033 \\
$\mathrm{NO}_{3}^{-}$ & 0.139 & - \\
$\mathrm{Cl}^{-}$ & 0.334 & 0.0146 \\
\hline
\end{tabular}

of the electrolyte used, the dissolution peak always appeared at the same potential of $-0.50 \mathrm{~V}$. Table 2 shows the total charge $\left(\mathrm{RVC}-Q_{\mathrm{A}}\right)$ calculated under these peaks. The highest charge, corresponding to dissolution of the largest amount of the $\mathrm{Pb}$ deposit, was observed for the chloride-containing electrolyte: 0.334 $\mathrm{mC}$. A very small peak with a low associated charge $(0.019 \mathrm{mC})$ for a small amount of $\mathrm{Pb}$ deposit, was observed in the sulfate-containing electrolyte. This leads us to conclude that the amount of $\mathrm{Pb}$ deposit on RVC electrode, formed from different electrolytes, decreases progressively in the order chloride to nitrate and to sulfate electrolytes. This conclusion agrees with our data for the efficiency of $\mathrm{Pb}(\mathrm{II})$ removal from different electrolyte solutions (electrolysis) as reported in the previous section.

\subsection{Cyclic voltammetry on the FVC electrode}

Employment of the FVC electrode in our study was motivated by a possibility to characterize the lead deposit by other surface sensitive techniques, i.e. such is AFM. As demonstrated in many studies, the AFM analysis offers many valuable data concerning deposit surface morphology and mechanism of growth [19-27]. However, the RVC electrodes due to specific surface characteristics (large porosity) are not really convenient for the AFM analysis. Therefore, we used the FVC instead of RVC electrode. Although we substituted the FVC for the RVC electrode, it was not clear that the two types of electrodes would provide equivalent and interchangeable data due to possible differences in the electrochemical behavior (surface physical-chemical characteristics) important during the $\mathrm{Pb}$ (II) deposition process. Surface preparation (polishing, electroactivacion, etc.) and surface characteristics of VC electrodes, in general, can have a significant influence on the pathway and kinetics of the electrode reactions [29-32]. Despite numerous studies using VC electrodes, no relevant conclusions have been reported concerning the metal deposition processes on their surfaces. The issue is quite important since RVC electrodes are often the choice in industry for technological purpose, because of its great relationship between specific area and volume electrode. Other type of VC electrodes such as mechanically polished VC, FVC and electroactivated VC electrodes serve as model electrode surfaces in research. We chose to perform cyclic voltammetry using FVC electrodes, to determine if the same trend for the efficiency of $\mathrm{Pb}$ deposit formation observed with the RVC electrode would be reproduced. Fig. 3 shows cyclic voltammograms for $\mathrm{Pb}(\mathrm{II})$ containing electrolyte solutions (I) $0.5 \mathrm{M} \mathrm{NaCl}$ and (II) $0.5 \mathrm{M} \mathrm{Na}_{2} \mathrm{SO}_{4}$. Although both voltammograms essentially describe the same processes of $\mathrm{Pb}$ (II) deposition and dissolution of the $\mathrm{Pb}$ on the FVC surface, 


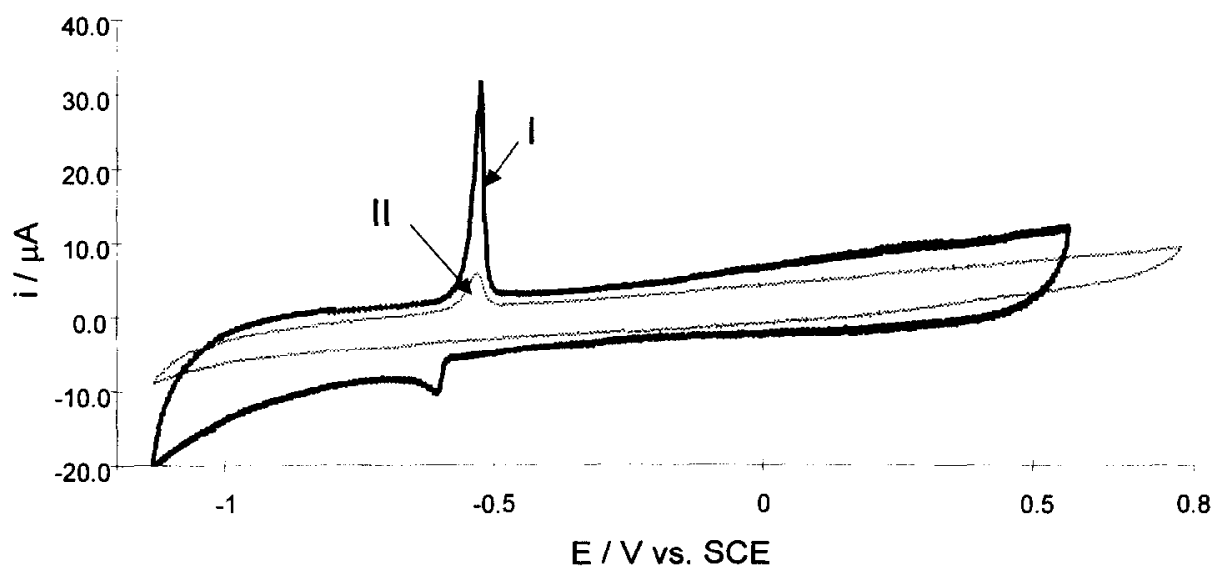

Fig. 3. Voltammograms for FVC electrode, obtained in $0.024 \mathrm{mM} \mathrm{Pb(II)} \mathrm{solution} \mathrm{in:} \mathrm{(I)} \mathrm{chloride} \mathrm{and} \mathrm{(II)} \mathrm{sulfate.} \mathrm{The} \mathrm{scan} \mathrm{rate} \mathrm{is}$ $5 \mathrm{mV} / \mathrm{s}$.

the difference according to the electrolyte used is obvious. Voltammograms recorded in $\mathrm{NaCl}$ electrolyte possessed two well-defined peaks. The first peak at $-0.60 \mathrm{~V}$ (cathodic direction) is related to $\mathrm{Pb}(\mathrm{II})$ deposition and another at $-0.55 \mathrm{~V}$ (anodic scarl), is related to the $\mathrm{Pb}$ deposit dissolution. The voltammogram related to the sulfate electrolyte (curve II) with a significantly smaller capacitive current and largely diminished $\mathrm{Pb}$ deposit dissolution peak, does not even present the $\mathrm{Pb}$ (II) deposition peak. In terms of the total charge evaluated under dissolution peaks (anodic scan Fig. 3), it is interesting to note that the voltannmetric peak obtained in the chloride-containing electrolyte (I), is associated with a charge four times greater than the same peak for the sulfatecontaining electrolyte (II) (see Table 2, FVC- $Q_{\mathrm{A}}$ ). This leads us to conclude that during the voltammetric scan, four times more $\mathrm{Pb}$ deposit was formed from the chloride solution than from the sulfate solution. It also confirms our findings, above, that $\mathrm{Pb}(\mathrm{II})$-depletion and formation of the $\mathrm{Pb}$ deposit on the $\mathrm{VC}$ electrode surface is strongly influenced by the composition of the electrolyte solution, favoring the deposition process in the chloride media. It also shows that in respect to the $\mathrm{Pb}(\mathrm{II})$ deposition process, no significant difference in the electrochemical behavior is expected between the RVC and FVC electrodes. Under our controlled experimental conditions, FVC and RVC. behave very similarly. More complete studies involving the different electrode surface pretreatment such as mechanical polishing, electrochemical and chemical activation, are in progress in our laboratory.

\subsection{AFM visualization of the Pb deposit at the FVC electrode surface}

AFM was used to reveal surface morphology of the $\mathrm{Pb}$ deposit, in order to elucidate the mechanism of metal-deposit formation process (electrocrystallization and growth) on the VC electrode surface. In these experiments, FVC electrodes were used exclusively. The $\mathrm{Pb}$ deposit was prepared using the constant potential method. In different electrolytes, the FVC electrode was exposed to different potentials for the period of $5 \mathrm{~s}$. This relatively short deposition time led to the formation of a small amount of deposit onto the FVC electrode with a relatively smooth surface, convenient for AFM analysis. As in the case of electrolysis of $\mathrm{Pb}$ (II) on RVC described above (Table 1), deposition of $\mathrm{Pb}$ (II) from sulfate electrolyte was also associated with greater current and charge than from the other electrolytes. In the case of the chloride-containing electrolyte, the total current flow was about three times less than in the sulfate media.

AFM images, indicated a difference in the surface morphology between $\mathrm{Pb}$ deposit prepared differently. Fig. 4 shows the set of characteristic AFM images obtained for deposit free (a) and deposit covered (b-d) FVC electrode surface. $\mathrm{Pb}$ deposits visualized in images $b-d$ were prepared from nitrate, chloride and sulfate electrolytes, respectively. As seen from AFM images, the electrode surface layer, whether deposit free or deposit covered, always possessed some kind of granular structure. This indicates that $\mathrm{Pb}$ (II) deposition from all electrolytes can be associated with some kind of 3-D deposit formation. The size and shape of the deposited grains, or clusters, however show the influence of the electrolyte composition, related to the differences in the deposit formation mechanism. 

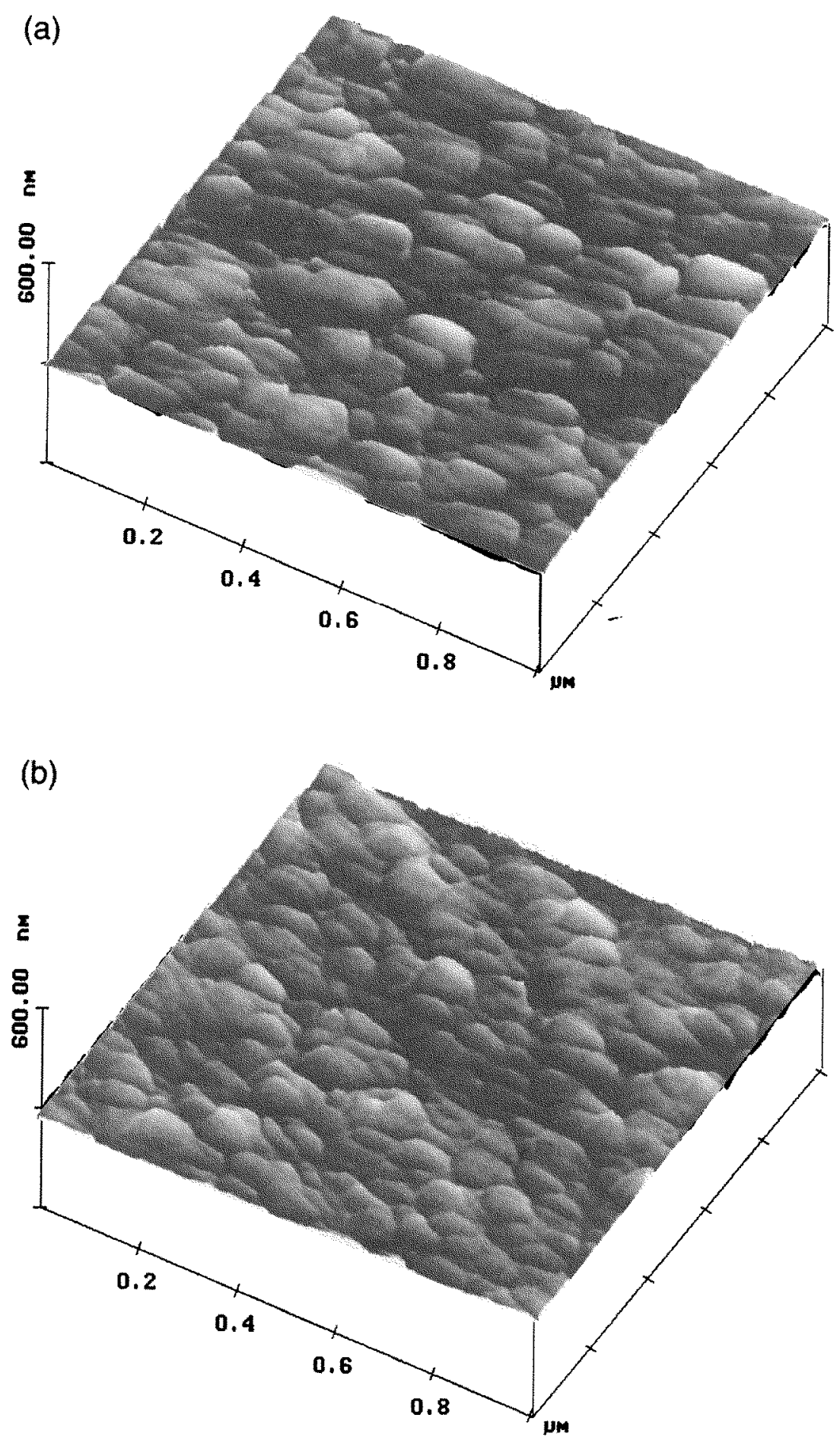

Fig. 4. AFM images of the $\mathrm{Pb}$ deposit-free (a) and deposit covered FVC electrode surface (b-d). Deposition was carried out from $0.024 \mathrm{mM} \mathrm{Pb}(\mathrm{II})$ in different electrolyte solutions: (b) nitrate, (c) chloride and (d) sulfate by 5 s electrolysis at constant potential method (other conditions as in Table 1). 

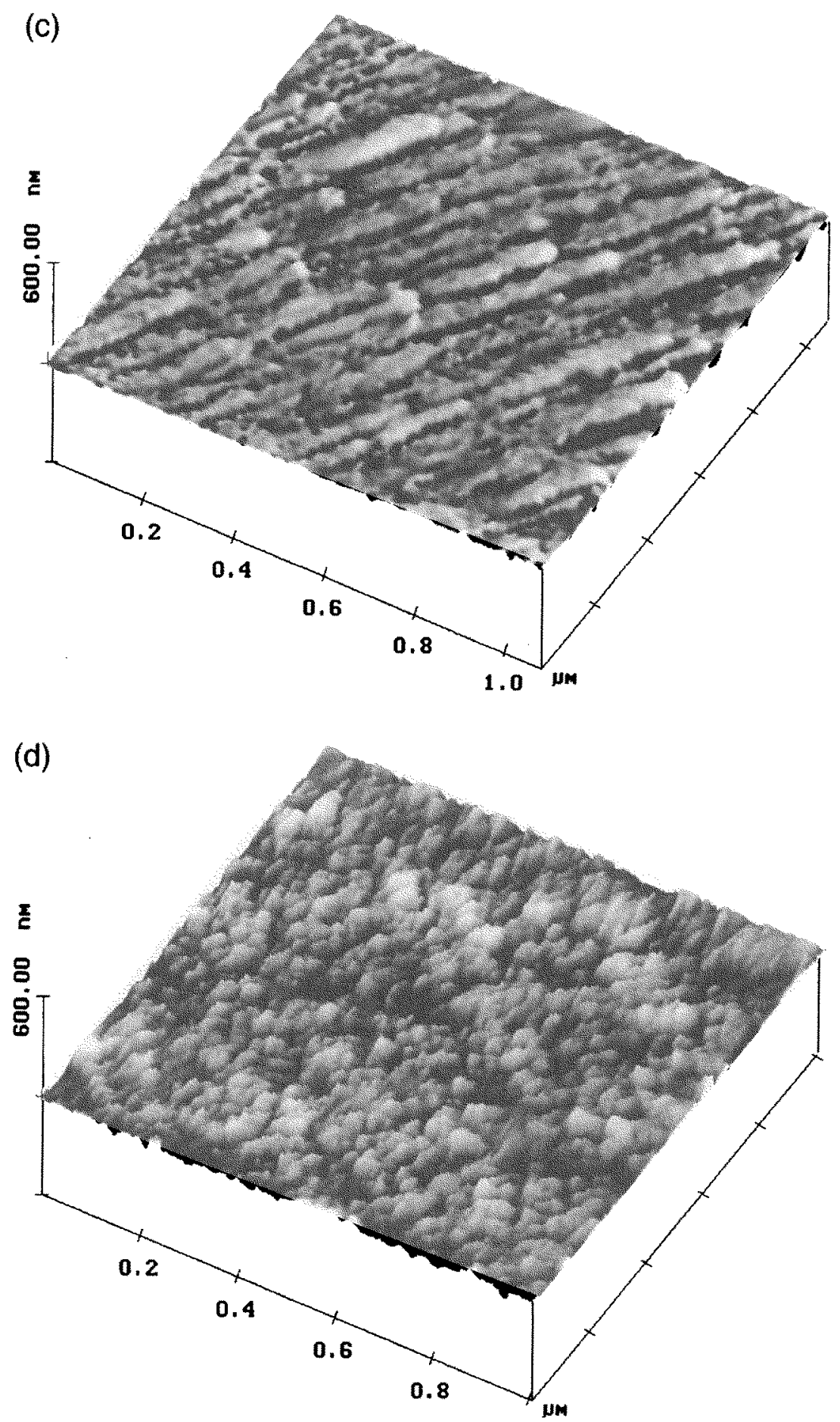

Fig. 4 (continued). 
The $\mathrm{Pb}(\mathrm{II})$ deposit formed from the nitrate electrolyte (Fig. 4b) had surface morphology similar to the deposit free FVC electrode. The surface layer consisted of ellipsoidal type of grains, $120 \mathrm{~nm}$ long and 50-100 $\mathrm{nm}$ wide. A similar texture was found for the bare FVC electrode surface (Fig. 4a). The RMS(Rq) (the root-mean-square) function [33], defined as a standard deviation of the height, calculated from all points obtained during a given scan, was used here as a measure of the surface roughness and indicated some difference in the surface roughness between these two surfaces $\left(6.7 \pm 0.5 \mathrm{~nm}\right.$, for lead deposit in $\mathrm{NO}_{3}^{-}$electrolyte and $10.4 \pm 0.5 \mathrm{~nm}$ for bare electrode surface). We concluded that $\mathrm{Pb}(\mathrm{II})$ deposition form the nitrate electrolyte resulted in the electrode surface smoothening. The same trend was also observed for other samples. However, deposits formed from the sulfate and chloride electrolytes, appears to be slightly rougher than one formed in the nitrate electrolyte. Equal $\operatorname{RMS}(\mathrm{Rq})$ values were found $(8.66 \pm 0.5 \mathrm{~nm})$ for both surfaces.

A detail inspection of the AFM images revealed differences in surface morphology, considering the size and shape of the major surface features. The $\mathrm{Pb}$ deposit formed from the chloride electrolyte possessed two type of characteristic surface features, the large ellipsoidal grains $(350-420 \mathrm{~nm}$ diameter) and the small, round shape clusters of only $20 \mathrm{~nm}$ diameter (Fig. 4c). Larger grains were formed apparently by annealing or smoothing of the small clusters, in a 2-D manner. As described in other studies, chloride is expected to exhibit such behavior due to strong interaction with a metal surface. Details of the surface annealing phenomenon caused by anion enhanced surface diffusion and deposit leveling mechanism, have been amply discussed previously [34-38]. This chloride enhanced surface mobility possibly results in a better packing of the metal deposit at the electrode surface, which ultimately contribute to the higher efficiency of the $\mathrm{Pb}(\mathrm{II})$ removal process from the chloride-containing solutions.

Another interesting explanation for greater efficiency of metal removal from chloride-containing electrolytes is the increased number of nuclei at the VC surface during the deposition process due to presence of chloride in the deposition bath. As studied and reported by Mostany et al. [17], halides could coadsorb with lead at the VC surface, at the deposition potentials and provide new precursor sites for further lead nucleation. The authors suggest that this coadsorption effect does not change the kinetics of deposit growth, but is expected to influence the deposit characteristics, including the deposit surface morphology. The effect was associated exclusively to the halides. Along the same line, Ponce de Leon and Pletcher [2], showed that the presence of chloride in the electrolyte solution may led to improved performance (higher efficiency) for removal of lead from aqueous solutions.

In contrast to the deposition from chloride, our AFM images revealed that deposits formed from the sulfate electrolyte contained $\mathrm{Pb}$ clusters of intact, genuine 3-D shape, with a size of about $35-45 \mathrm{~nm}$ (Fig. 4d). This is half the size of the grains seen at the bare FVC electrode substrate (Fig. 4a), indicating the presence of more than one active site for the $\mathrm{Pb}$ (II) deposition process per single FVC grain. AFM images also showed that $\mathrm{Pb}$ clusters formed in sulfate solutions had no tendency to merge or associate in any way so that the surface looked different from one formed in a chloride solution. In the sulfate media, newly born $\mathrm{Pb}$ clusters are isolated from each other due to immediate formation of the lead salt $\mathrm{PbSO}_{4}[39]$ on the cluster surface $[40,41]$. Pb clusters are thus passivated, encapsulated in an insoluble, poorly conductive salt film, which in terms of the observed surface morphology, leads to the preservation of genuine 3-D clusters. Surface poisoning and formation of a passivated adlayer around the genuine lead clusters, is most likely the reason for a decrease in the $\mathrm{Pb}$ (II) removal efficiency and formation of low density deposits. In order to proceed with the deposition process on such surface, the insoluble salt must be removed from the lead clusters. This process most probably requires great energy consumption. This also, supports electrochemical findings of higher energy consuming during the lead deposition from the sulfate solutions than from other electrolytes.

AFM visualization revealed differences in the surface morphology for $\mathrm{Pb}$ deposits prepared from different electrolytes. The most compact $\mathrm{Pb}$ adlayer with almost 2-D morphological characteristics was prepared from the chloride electrolyte. In terms of electrochemical data, this corresponds to the highest efficiency of $\mathrm{Pb}$ (II) removal from the aqueous solution. AFM observations support the electrochemical findings, indicating that the explanation for such behavior is the nature and mechanism of the $\mathrm{Pb}(\mathrm{II})$ deposition process. We, therefore, plan to continue to study the mechanism and kinetics of $\mathrm{Pb}(\mathrm{II})$ deposition onto $\mathrm{VC}$ electrodes. In particular, it will be interesting to see deposit behavior at the early stages of deposition, and try to visualize differences in number of nuclei at the electrode surface with different electrolytes. Although ex situ AFM analysis proved to be an excellent tool for $\mathrm{Pb}$ (II) deposit characterization, our further studies are unlikely to include in situ AFM or in situ STM techniques.

\section{Conclusions}

Electrolytic removal of $\mathrm{Pb}(\mathrm{II})$ from aqueous solutions containing the different electrolytes nitrate, 
chloride or sulfate, by electrolysis onto reticulated vitreous carbon electrode (RVC), showed that higher removal efficiency was achieved in the case of chloridecontaining electrolytes. Removal of $\mathrm{Pb}$ (II) from the sulfate electrolytes required a large current flow through the electrolytic cell and was the least efficient and the most energy consuming process. To understand the origin of the differences and the influence of anions during the lead removal process, we examined the $\mathrm{Pb}$ deposit formation and deposit characterization on the vitreous carbon (VC) electrode using cyclic voltammetry and the atomic force microscopy (AFM).

Our analyses included the RVC electrodes, important for industrial use, as well as the fractured vitreous carbon (FVC) electrodes. By determining the similarity in results for the two types of electrodes, we established that the FVC can be used as a model electrode for studying $\mathrm{RVC}$ electrodes under conditions and with techniques where using the RVC would be inconvenient.

The RVC and FVC, posses similar structure and physical-chemical properties since neither was passed through the pretreatment process characteristics for vitreous carbon electrodes (polishing, electrochemical activation, etc.). Our cyclic voltammetry for RVC and FVC electrodes in different $\mathrm{Pb}(\mathrm{II})$ electrolytes confirmed the similarity of these two electrode types. Furthermore, the analysis of the lead-deposit dissolution behavior shows that in the chloride solution, a significantly larger amount of deposit was formed than in the sulfate electrolyte. This is in agreement with data concerning the lead electrolysis efficiency and shows that the FVC electrode can be a laboratory replacement for the widely used RVC electrode.

Visualization of the lead deposit on FVC electrode surface using the AFM technique also confirms our electrochemical findings. Deposits formed from different electrolyte solutions possess different surface morphology characteristics, indicating different mechanism of formation or at least different kinds of interaction between the metal adlayer and the adsorbed anions. A well spread deposit all over the electrode surface in the form of 2-D film was found in the case of the chloridecontaining electrolyte. The lead deposit formed from nitrate electrolyte appeared to have similar surface morphology similar to the bare FVC electrode.

In the case of the sulfate-containing electrolyte, AFM revealed numerous, very small lead clusters, randomly distributed at the electrode surface. The observed differences in surface morphology among the lead deposit formed from different electrolyte solutions, have been attributed to the different interactions between solution anions and the metal adlayers or even the bare electrode surface. These interactions directly influence the deposit packing density and the efficiency of the electrolysis process. Deposition from sulfate solutions was inhibited by formation of the passivated salt adlayer over the lead clusters.

\section{Acknowledgements}

This research project was financially supported by CONACyT (Projects No. 0913E-P, L0081-E9608 and 400200-5-4250PA) G. Carreño and E. Sosa acknowledge CONACyT for their scholarships.

\section{References}

[1] D. Pletcher, F.C. Walsh, in: Industrial Electrochemistry, 2nd ed., Blackies, Bishopbriggs, Glasgow, 1993.

[2] C. Ponce de León, D. Pletcher, Electrochim. Acta 41 (1996) 533.

[3] F.C. Walsh, The role of the rotating cylinder electrode reactor in metal-ion removal, in: J.D. Genders, N. Weinberg (Eds.), Electrochemical Technology for a Cleaner Environment, Chap. 5, The Electrosynthesis Co., Lancaster, NJ, 1992.

[4] G. Lacoste, Dechema Monogr. 123 (1990) 411.

[5] F.C. Walsh, in: A First Course in Electrochemical Engineering, The Flectrochemical Consultancy, 1993.

[6] A.T. Kuhn, (Ed.), Industrial Electrochemical Processes. Elsevier, Amsterdam, 1971.

[7] J.O'M. Bockris, (Ed.), Electrochemistry of Cleaner Environments, Plenum Press, New York, 1972.

[8] R. Kammel, H.W. Lieber, Galvanotechn. 68 (1977) 413

[9] G. Kreysa, Metalloberflache 35 (1981) 211.

[10] M. Palomar-Pardave, M.T. Ramirez, I. Gonzalez, A. Serruya, B.R. Scharifker, J. Electrochem. Soc. 143 (1996) 1551.

[11] D.M. Kolb, Schering Lecture's Publications, vol. 2, Schering Research Foundation, Berlin, 1991, pp. 1-34.

[12] O.M. Magnussen, J. Hotlos, G. Beitel, D.M. Kolb, R.J. Behm, J. Vac. Sci. Technol. B 9 (1991) 969.

[13] N. Batina, T. Will, D.M. Kolb, Faraday Discuss. 94 (1992) 93.

[14] H.S. Yee, H.D. Abruna, Langmuir 9 (1993) 2460.

[15] N. Markovic, H.A. Gasteiger, C.A. Lucas, I.M. Tidswell, P.N. Ross Jr., Surf. Sci. 335 (1995) 91.

[16] A. Montillet, J. Comiti, J. Legrand, J. Appl. Electrochem. 24 (1994) 27.

[17] J. Mostany, J. Parra. B. Scharifker, J. Appl. Electrochem. 16 (1986) 333.

[18] E. Sosa, M.T. Oropeza, C. Ponce de Leon, I. Gonzalez, $\mathrm{N}$. Batina, in preparation.

[19] R.J. Phillips, T.D. Golden, M.G. Shumsky, J.A. Switzer, J. Electrochem. Soc. 141 (1994) 2391.

[20] E. Gomez, E. Valles, P. Gorostiza, J. Servat, F. Sanz, J. Electrochem. Soc. 142 (1995) 4091.

[21] D. Aurbach. Y. Cohen, J. Electrochem. Soc. 143 (1996) 3525 .

[22] S.N. Maganov. M.H. Whangbo (Eds.), Surface Analysis with STM and AFM, VCH, Weinheim, New York, 1996.

[23] E.D. Eliadis, R.G. Nuzzo, A.G. Gewirth, R.C. Alkire. J. Electrochem. Soc. 144 (1997) 96. 
[24] Y.G. Li, A. Lasia, J. Appl. Electrochem. 27 (1997) 643.

[25] A. Gewirth, B.K. Niece, Chem. Rev. 97 (1997) 1129.

[26] M. Miranda-Hernandez, M. Palomar-Pardave, N. Batina, I. Gonzalez, J. Electroanal. Chem. 443 (1998) 81.

[27] M. Palomar-Pardave, M. Miranda-Hernandez, 1. Gonzalez, N. Batina, Surf. Sci. 399 (1998) 80

[28] G. Carreno, I. Rodríguez, M.T. Oropeza, C. Ponce de Leon, 1. Gonzalez, Proceedings of 10th Congreso Nacional de la Socjedad Mexicana de Electroqumica, San Luis Potosi, Mexico, 1995, pp. 201-205.

[29] R.J. Rice, C. Allred, R. McCreery, J. Electroanal. Chem. 263 (1989) 163.

[30] R.J. Rice, N.M. Pontikos, R.L. McCreery, J. Am. Chem. Soc. 112 (1990) 4617.

[31] R.L. McCreery, in: A.J. Bard (Ed.), Electroanalytical Chemistry, vol. 17. Marcel Dekker. Inc., New York, 1991.

[32] M.T. McDermott, C.A. McDermott, R.L. McCreery, Anal. Chem. 65 (1993) 937.

[33] Digital Instruments, Nanoscope III, manua].
[34] J.L. Stickney, I. Villegas, C.B. Ehlers, J. Am. Chem. Soc. 111 (1989) 6473.

[35] J.L. Stickney, C.B. Ehlers, J. Vac. Sci. Technol. A 7 (1989) 1801.

[36] D.R. Peale, B.H. Cooper, J. Vac. Sci. Technol, A 10 (1992) 2210

[37] M.P. Garcia, M.M. Gomez, R.C. Salvarezza, A.J. Arvia, J. Electroanal. Chem. 347 (1993) 237.

[38] D.M. Kolb, A.S. Dakkouri, N. Batina, in: A.A. Gewirth, H. Siegenthaler (Eds.), The Surface Structure of Gold Single Crystal Electrodes. Nanoscale Probes of the Solid/ Liquid Interface, Vol.E., NATO ASI Series C, Sophia Antipolis, Kluwer, Dordrecht. 1995, p. 288.

[39] Y. Guo, J. Chen, L. Li, J. Electrochem. Soc. 139 (1992) L99.

[40] F.E. Varela, L.M. Gassa, J.R. Vilche, J. Appl. Electrochem. 25 (1995) 358.

[41] F.E. Varela, L.M. Gassa, J.R. Vilche, J. Appl. Flectrochem. 25 (1995) 364 